\title{
LOS CONFLICTOS SOCIALES DERIVADOS DE LA EXTRACCIÓN MINERA: ESTUDIO DE CASO DEL EJIDO LOS CACAOS EN CHIAPAS, MÉXICO
}

\author{
Yoame Ramírez Ramos* \\ Alma Estela Martínez Borrego**

\section{RESUMEN}

El presente estudio, da a conocer el fenómeno de la inserción del extractivismo minero en la región Soconusco en el siglo XXI, un área rural sujeta a la política gubernamental conservacionista ubicada en la frontera sur de México. Desde una perspectiva teóricametodológica de carácter interdisciplinaria expone el panorama minero regional, privilegia la óptica etnográfica y el enfoque de comunidad para dar cuenta de los cambios en las formas de vida y las distintas valoraciones que detonan la disputa por los recursos a partir del caso de estudio del ejido Los Cacaos. Con esto, se observa el surgimiento de redes y relaciones de actores en un campo de conflicto que debido a la controversia y distintos sucesos que se exponen en el texto, mantiene suspendida la minería.

Palabras clave: Conflicto, ecología política, estudios rurales, extractivismo minero.

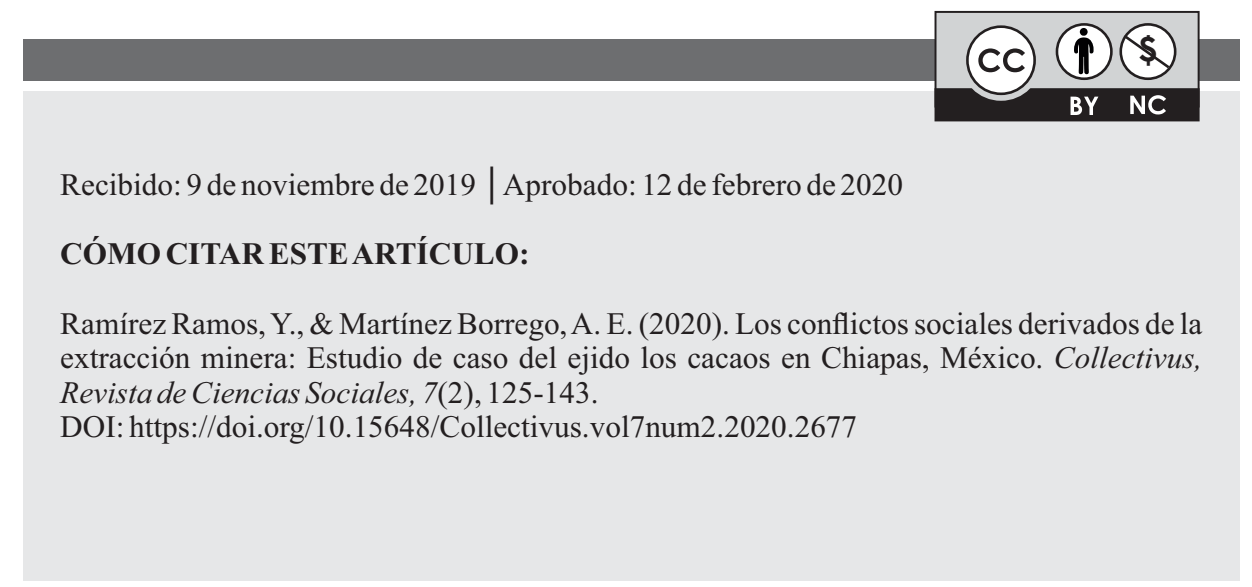

\footnotetext{
* Doctorante del Programa de Posgrado en Antropología, Universidad Nacional Autónoma de México. Unidad de Posgrado, Edificio F primer nivel, Ciudad Universitaria, C.P. 04510. E-mail: yoamer@hotmail.com.

** Doctorado en Ciencia Social por la Universidad de París, Francia. Investigadora del Instituto de Investigaciones Sociales, Universidad Nacional Autónoma de México. Circuito Mtro. Mario de la Cueva s/n, Ciudad Universitaria, C.P. 04510. E-mail: mborrego@servidor.unam.mx
} 


\title{
SOCIAL CONFLICTS DERIVED FROM MINING EXTRACTION: CASE STUDY IN THE LOS CACAOS EJIDO IN CHIAPAS, MÉXICO
}

\begin{abstract}
The present study, reveals the phenomenon of the insertion of mining extractivism in the Soconusco region in the 21 st century, a rural area subject to the conservationist government policy located on the southern border of Mexico. From an interdisciplinary theoretical-methodological perspective, it exposes the regional mining panorama, privileges the ethnographic perspective and the community approach to account for the changes in the ways of life and the different evaluations that trigger the dispute for resources based on the case study of the ejido Los Cacaos. With this, the emergence of networks and relationships of actors is observed in a conflict field that, due to the controversy and different events that are exposed in the text, keeps mining suspended.
\end{abstract}

Keywords: conflict, mining extractivism, political ecology, rural studies.

\section{Introducción}

La actividad minera se desarrolló en el ejido, lugar conocido con el nombre de Los Cacaos, situado en el municipio de Acacoyagua en la región del Soconusco en Chiapas (México), en el año 2009, en pleno auge del boom minero. Por esta situación, se realizaron varias concesiones a empresas para la extracción de minerales en nuevos espacios, debido a que las políticas y los planes de gobierno, incentivaron la promoción de las ventajas competitivas que determinaron el perfil extractivista minero. Entre el año 2000, y el año 2017, en Chiapas, fueron otorgadas un mínimo de 153 concesiones que en la actualidad hacen un aproximado de 1,528,853.24 hectáreas, las cuales se concentran en la CostaSierra, en un área equivalente al $20.85 \%$ de la superficie estatal y abarca grandes extensiones prioritarias para la conservación ecológica.

Como resultado de ello, se insertaron los capitales mineros nacionales y trasnacionales, entre los cuales destacan: Linear Gold, Radius Gold Corp, subsidiarias de Minera Frisco, Grupo Salinas, las canadienses BlackFire y Minera Caracol, empresas denunciadas por corrupción, criminalización y asesinato de opositores mineros en Chiapas, ante las controversias e impacto territorial provocado por los procesos de extracción de barita en el municipio de Chicomuselo, y también distintas subsidiarias con presencia regional que exportan hacia China.

En este sentido, la Secretaría de Economía otorgó una concesión para desarrollar la minería en el ejido por cincuenta años (2009 a 2059), en favor de la empresa subsidiaria El Puntal de capital chino. En el nivel local, esto trajo el comienzo de una relación empresa-comunidad, la cual inició con un proceso de acercamiento con las autoridades agrarias, en él se ofreció una serie de ventajas en caso de que se aprobara la realización de las actividades de extracción en el núcleo agrario, para después llevar a cabo la presentación de esas intenciones ante la mayoría de los ejidatarios en una asamblea en el año 2009.

Estos sucesos, derivaron en la aceptación de las actividades de exploración y posterior explotación minera en la comunidad, mediante la celebración de una asamblea ejidal extraordinaria, logrando la anuencia en condiciones asimétricas, es decir, con acuerdos de beneficios diferenciados para los ejidatarios y los demás habitantes en el interior de la estructura social. 
Lo anterior, define una relación de poder a la cual accedieron los lugareños, basada en compromisos ofrecidos como ventajas individuales y comunitarias por parte de la empresa, entre las cuales destaca: la realización de obras públicas, trabajo dentro de la mina y como transportadores del mineral, la renta de algunas parcelas para resguardo de insumos, el manejo de maquinaria para la destrucción de rocas, el otorgamiento de regalías, y otras actividades que generaron pocas ganancias y empleos limitados. De igual manera, esta situación fue cuestionada con el paso del tiempo, debido a que hubo una extracción permanente de minerales en las zonas selváticas que forman parte de la Reserva de la Biósfera El Triunfo, evidenciada por la devastación del área.

Al mismo tiempo, la transformación del territorio y la apropiación de lugares que sustentaban los ciclos productivos del mamey, café y cacao, pilares fundamentales para la reproducción económica y de las formas de vida de la comunidad. El vertido de residuos de la mina en los ríos; la aparición de daños importantes en la salud, así como las actividades agropecuarias a causa de la minería, generaron una tensión en Los Cacaos, sobre todo de cara a los beneficios diferenciados en el interior del núcleo agrario. Las ventajas focalizadas que evidenciaron tratos incumplidos, sumado esto a la obtención de pocas o nulas ganancias, dieron pie a que los tratos con la empresa fueran percibidos por cierta parte de la población como un "engaño", al no cumplirse con los acuerdos y el arribo de los "beneficios" ofrecidos como ventajas de su inserción, sobre todo luego de la transformación de los referentes espaciales y las afectaciones causadas a la población.

De esta manera, surgen conflictos expresados en las valoraciones divergentes entre los habitantes, que mantienen en controversia las actividades de exploración y explotación minera en la comunidad. Por una parte, están quienes defienden la permanencia de la empresa minera, con el objetivo de obtener provecho de su vinculación con ella, y por otra, aquellos que defienden el territorio de la apropiación de los recursos naturales por parte de un actor externo, así como de los daños ambientales, sociales y personales asociados con su presencia.

La magnitud de este problema tiene implicaciones a nivel regional, debido a que las concesiones, la extracción de minerales, la apropiación espacial y las transformaciones de los entornos, implican también otros acuerdos, tránsitos y relaciones que exceden el área ejidal.

Por todo lo anterior, el objetivo principal de este estudio es explorar los conflictos sociales derivados de la extracción minera, y de qué manera se estructuran las relaciones de poder que permiten la ocupación y apropiación del territorio en el ejido Los Cacaos. Asimismo, identificar cuáles son las valoraciones e intereses que entran en conflicto, y los actores e instituciones que intervienen en el mismo.

Como hipótesis general, se plantean los conflictos sociales derivados de la extracción minera: se presentan debido a las asimetrías de poder que permiten la instalación de la empresa minera El Puntal, como resultado de las relaciones de intercambio diferenciadas y que involucran las estructuras en el nivel municipal y local, que posibilitan la ocupación y apropiación del territorio por un actor externo a la comunidad. 


\section{Extractivismo minero y conflicto social: un acercamiento teórico}

En el siglo XXI, se ha intensificado el interés mercantil por los bienes minerales inmersos en territorios estratégicos, con el fin de sostener y expandir las relaciones de capital, lo cual implica, entre otras cosas: mercantilización de tierras, privatización de derechos, supresión de formas de vida y de bienes naturales, y dinámicas de apropiación basadas en la acumulación por desposesión (Harvey, 2006, p.26), las cuales son características del denominado extractivismo minero.

Las experiencias recientes, han evidenciado transformaciones de los entornos ambientales y sociales asociadas a los megaproyectos dependientes de tecnología de punta. Esto ha originado acciones colectivas comunitarias en oposición al desarrollo de esta actividad (Martínez Alier, 2004), esto es, el despliegue de valoraciones de tipo ecológico y cultural que tienen como base el derecho a la subsistencia económica de las poblaciones (ob. Cit.), centradas en la reivindicación del territorio como espacio de vida (Svampa, 2010; Rodríguez, 2010), sobre lo cual dan cuenta diversas investigaciones latinoamericanas planteadas desde la perspectiva de los movimientos sociales (Svampa, 2010; Silva, 2010; Lamberti, 2011).

Vale exponer que en el contexto mexicano, esta problemática ha sido foco de interés sobre todo desde la última década, debido a que entre los años 2001 y 2012, hubo un aumento inusitado de concesiones en nuevos territorios sin tradición minera, ya que se otorgaron 28,807 nuevos títulos en un total de 68.8 millones de hectáreas, y ante la intensificación de los niveles de extracción en las inmemorables regiones mineras, debido a la incorporación de tecnología de punta en este sector, por lo cual destacaron entonces las concesiones canadienses (71\%), estadounidenses (16\%) y chinas $(8 \%)$.

Como resultado de los impactos sociales, ante el ascenso de los percances ambientales asociados a la minería y la desatención gubernamental, como es el caso de la contaminación por derrames, han surgido distintos procesos organizativos, los cuales, aunque no son homogéneos, dan cuenta de nuevas formas de intermediación y negociación institucional para el establecimiento de la minería, como destaca (Rodríguez, 2010), en el caso de Carrizalillo, Guerrero.

Del mismo modo, exponen el surgimiento de estrategias organizativas comunitarias, y regionales en oposición a la misma, como se ejemplifica en el caso del territorio sagrado wixárica de Wirikuta, la Costa-Montaña de Guerrero y otros espacios con presencia indígena y campesina, por lo que estas disputas ya no solo expresan reivindicaciones relacionadas con la autonomía, sino que dan cuenta de la diversificación de los actores en las mismas, aunado a las estrategias, participación y espacios de acción, lo cual da cuenta del surgimiento de la Red Mexicana de Afectados por la Minería y su participación en organizaciones de carácter trasnacional.

Por tanto, en la región del Soconusco los acuerdos entre empresas y comunidades permitieron la inserción de la minería hace al menos una década, y en los últimos años las controversias por la apropiación de los entornos comunes han originado conflictos. Con el objetivo de profundizar en el análisis de los problemas asociados a la minería y sobre los actores en disputa, se retoman las nociones de conflicto y campo, para dar cuenta de las

\footnotetext{
${ }^{1}$ En palabras de Gudynas la minería contemporánea aborda: “...los emprendimientos que remueven o extraen enormes volúmenes de recursos naturales..., y que son exportados directamente sin ser procesados, o con un procesamiento o industrialización muy limitada" (2010, p.40).
} 
redes de relaciones que ahí se desarrollan y la acción de los sujetos en el territorio, cuyos comportamientos, intereses y lógicas de apropiación, nos permiten concebir el espacio como un campo de poder en constante construcción (Mançano, 2010).

El desarrollo del concepto de conflicto, por las disciplinas sociológica y antropológica en su vertiente estructural-funcional, profundizaron en las formas de integración social actor-sistema. En los años cincuenta, la sociología de Talcott Parsons expuso al conflicto como resultado del comportamiento desviado de los roles. En el caso de la antropología, el interés por mostrar las morfologías sociales y la articulación orgánica de la vida social, fue central en las etnografías de Malinowski y Radcliffe-Brown, entre otros.

Posteriormente, los aportes críticos dan cuenta de los límites de la propuesta estructuralista, en especial la Escuela de Manchester, la cual aglutinó investigaciones antropológicas en contextos coloniales; aun cuando centraron sus estudios en los mecanismos de cohesión y equilibrio estructural, que dan como conclusión del conflicto el surgimiento de las instituciones modernas, las etnografías nos permiten distinguir la interacción de agrupaciones con valores e intereses comunes y diferentes (Evans-Pritchard, 2010, p.420). Al mismo tiempo, para Gluckman la fisión y fusión caracteriza la relación que vincula grupos, posiciones sociales y relaciones económicas diferenciadas (2003, pp.11-14).

Sin embargo, Van Velsen considera que las propuestas anteriores estudiaron el conflicto desde las estructuras y no como un proceso, lo cual imposibilitaba concebirle como un factor de cambio social. En ese sentido, considera que, para dar cuenta de las variaciones de valoración, tensiones intergeneracionales y nuevos comportamientos desde el enfoque de la comunidad, es central involucrar la acción del individuo (Van Velsen, 2007, p.7).

En este punto, su propuesta converge con el funcionalismo crítico y los aportes de Georg Simmel, quien reconoce al conflicto, al antagonismo, a la acción recíproca común, el consenso y el disenso, que generan y modifican comunidades de intereses, formas de socialización, organización y pautas de cooperación/conflicto, como inherentes a la vida social. En su propuesta analítica, el estudio del conflicto como hecho sui generis, debe distinguir las relaciones antagónicas, trascendiendo el principio de unidad e integración orgánica individuo-sociedad en el nivel estructural, para evidenciar las significaciones opuestas, la hostilidad, la competencia y el desacuerdo como expresión de adversariedad (Simmel, 2010, p.18).

Lo anterior fue retomado por Lewis Coser, para ahondar en la diferenciación entre conflictos al interior de una estructura social y los que se originan con estructuras externas, para discernir el comportamiento dispar de las agrupaciones: cohesión y oposición en relación con el factor de amenaza interior o exterior. En ese sentido, el conflicto implica varias formas de disputa e interacción de las agrupaciones que surgen con intereses y objetivos dentro de un marco de relaciones antagonistas, involucra valores, recursos y relaciones interpersonales no exentas de poder, por lo cual es un factor de cambio social (Coser, 1961, p.174).

Si bien, la sociología del conflicto ha sido productiva sobre todo desde la posguerra, los planteamientos anteriores fundan gran parte de las propuestas contemporáneas, que ponen una especial distancia a la dominación como centro de análisis y brindan importancia analítica a los sujetos como agentes centrales de los conflictos sociales (Touraine, 1994, pp.238-240). 
Tomando en cuenta lo anterior, un conflicto es una disputa entre distintos grupos o actores en condiciones distintas de poder, que se oponen a los cambios que les afectan, o bien son expresión de necesidades y/o intereses que involucran la apropiación de bienes simbólico-culturales e implican coaliciones, compromisos y estrategias políticas (Abélés y Baradó, 2015, p.105).

La relación social, como adversarios en el espacio público (Schmitt, 1998, p.58) involucra las esferas materiales y simbólicas, cuyos lenguajes de valoración sacan a relucir los problemas que afectan, a partir de distintas prácticas (Balandier, 1969, p.41; Cohen, 1979, p.61; Díaz, 2005, p.107). Esto, da origen al campo del conflicto y a la arena política, en la cual se despliega la lucha orientada por la organización de los grupos implicados, al mismo tiempo, define la identidad del otro al diferenciarse de su enemigo (Schmitt, 1998: p.57). Así, los conflictos se manifiestan en escenarios específicos de interacción antagónica (Turner, 2002), y en lugares simbólicos que exponen la densidad de los problemas que le asocian a cada grupo.

De esa manera, en los conflictos desatados por el extractivismo minero se enfrentan intereses, necesidades y objetivos de actores sociales que pugnan por la apropiación, uso, transformación y control de los bienes naturales. La controversia se relaciona con el acceso, disponibilidad, calidad de los recursos, las valoraciones subjetivas y referentes de memoria, así como, con las condiciones ambientales del entorno y las económicas, las cuales afectan la vida de las personas. Por tanto, involucran la privación o deterioro de los recursos naturales como fuente de sustento y de atribuciones de valor, lo que genera intereses opuestos entre individuos o grupos en relación con su aprovechamiento y disposición, y con el acceso a los bienes necesarios para la supervivencia social.

Lo anterior, enmarca la emergencia de actores que se movilizan en defensa del espacio vital, reivindicado políticamente en relación con la importancia social y cultural de las atribuciones de valor del territorio, cuyas prácticas espaciales se entrelazan y dan cuenta de la relación del territorio e identidad, a partir de la noción de territorialidad (Masagualli y Bolaño, 2017). Los daños reales o simbólicos, adquieren significación desde la asociación de los elementos del entorno físico, y cuya destrucción o transformación impulsa el acto de su defensa. De acuerdo con (O'Connor, 2001), ello da cuenta de las contradicciones que confrontan las condiciones ambientales y las relaciones sociales, donde están en juego los modos de vida y los límites de la naturaleza vulnerados por las relaciones de capital, lo cual da por resultado la confrontación.

\section{La región Soconusco: de cacaotales, cafetales y minerales}

La región Soconusco, destacó históricamente por la fertilidad de sus tierras, ello incentivó el establecimiento del comercio continuo en el mercado internacional como una economía de enclave monocultivo, ${ }^{2}$ iniciada desde la Colonia para el abasto de cacao (Helding, en Damián, 1988), y sobre todo, tras la incorporación de la región a México (1882), y con la Ley de Colonización promovida por Díaz (1883), que permitieron la intensificación de la inversión de capitales extranjeros cafetaleros (Pohlenz, 1978, Spenser, 1998). Este impulso configuró las relaciones sociales y de poder regional del sistema finquero sostenido aún en la posrevolución.

${ }^{2}$ La producción de materias primas orientadas a la exportación (Cardoso y Faletto, 1994).

${ }^{3}$ En principio los finqueros obtenían la fuerza de trabajo forzada en Los Altos de Chiapas (Pohlenz, 1978, Renard, 1993, Spenser, 1998). 
Tras la disputa por el control territorial, por parte de un movimiento contrarrevolucionario (Damián, 1988), que se negaba a entregar los latifundios, se dio el reparto agrario y se crearon los primeros ejidos en torno a las fincas. Entre 1934 y 1940, se reestructuró el espacio geográfico al quitar el poder a los finqueros, lo cual tuvo como consecuencia la conformación de los campesinos como sujetos agrarios, cuyas formas de vida se sustentaron entonces en los ciclos agrarios relacionados con la producción de cacao y café.

El quiebre de los proyectos, enfocados en el desarrollo endógeno (Hernández, 1998), el proyecto de modernización del sector agrícola y las sucesivas políticas económicas neoliberales que se presentan a partir de los años ochenta del siglo XX, marcaron la emergencia de una oleada de grandes extensiones de monocultivos agroindustriales de exportación, entre los que destacan la palma de aceite, mango, caña de azúcar (Santacruz, 2009), así como la incorporación de la región en los procesos de migración laboral.

En años recientes, cuarenta y dos concesiones mineras han sido otorgadas en la región Soconusco, pues la tecnología ha permitido conocer la existencia de depósitos importantes, muchos de ellos ubicados en áreas de alto valor ecosistémico, y por lo mismo, foco de las políticas conservacionistas ambientales. Este es el caso del área, que comprende los municipios de Acacoyagua, Escuintla y Mapastepec, cuyos proyectos se asocian a la extracción de titanio (SE/SGM, 2015), se traslapan con las propiedades sociales de la tierra (ejidos y comunidades), coinciden con asentamientos poblacionales y confluyen con la presencia de ríos, que atraviesan la cuenca y las áreas naturales protegidas, como lo muestra el siguiente mapa.

Figura 1. Concesiones mineras en la región Soconusco

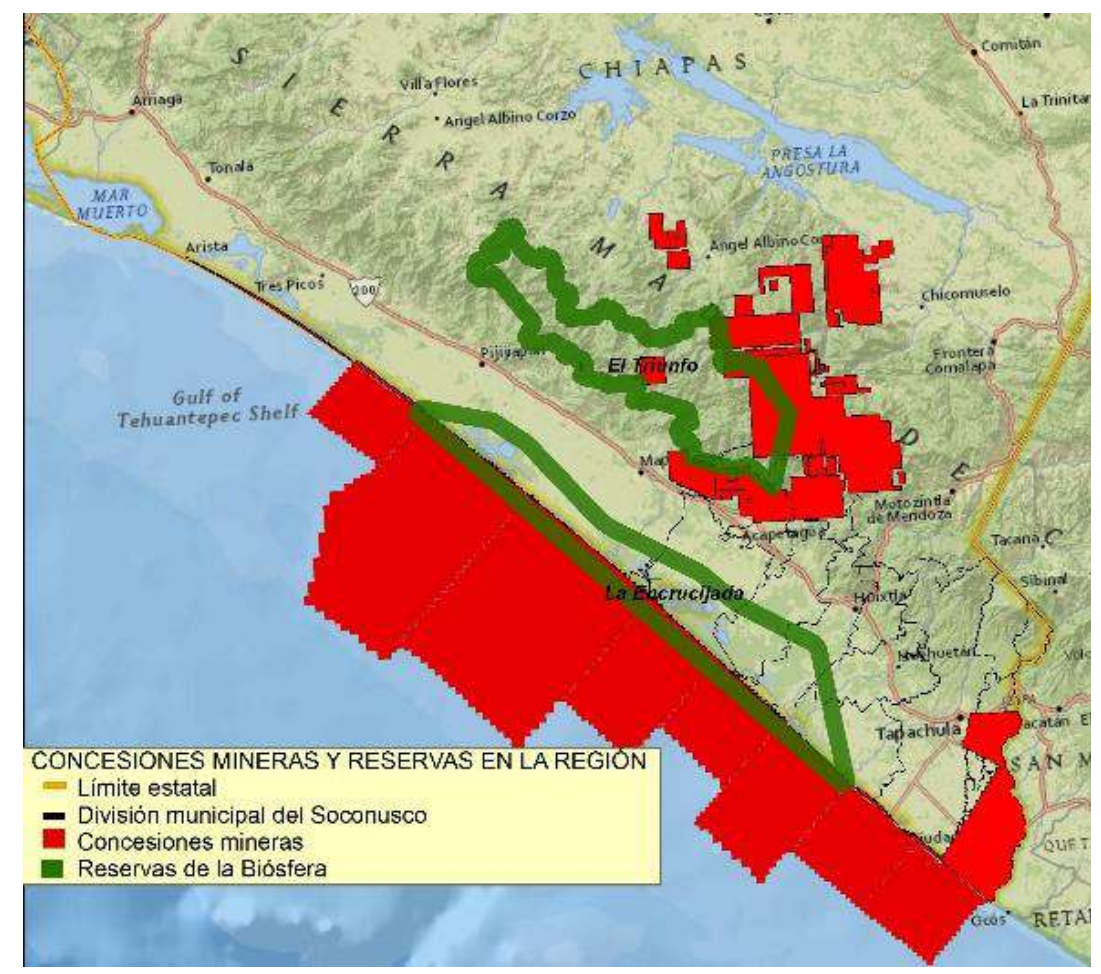

Fuente: Elaboración propia con base en INEGI (2017). Dirección General de Minas/ Dirección de Cartografía (2017a), CONANP (2017), y SIAM (2017). 


\section{El extractivismo minero en la región Soconusco}

La actividad minera, se insertó al menos hace una década en las comunidades rurales La Libertad, Los Cacaos y Nueva Francia, pertenecientes a los municipios de Acacoyagua y Escuintla. Como se mencionó, se dio una negociación de las empresas con las autoridades agrarias y con los ejidatarios para tener acceso a los territorios, cuestión que suscitó relaciones de intercambio al interior de ellas y también con las comunidades aledañas a las áreas concesionadas.

De acuerdo con los datos oficiales, no existen proyectos mineros activos en la región (SE/SGM, 2015), sin embargo, otras fuentes evidencian que la explotación a cielo abierto se ha intensificado desde el año 2012, en sitios localizados dentro de la Reserva de la Biósfera El Triunfo, o en la zona de amortiguamiento con una cercanía de dos kilómetros (Moreno y Abraján, 2016), motivo por el cual en los últimos años se han suscitado controversias regionales, a causa de sus efectos espaciales, sociales y ambientales.

Los cambios en la apariencia física de los ríos, que atraviesan la cuenca desde la sierra y descienden hacia la costa hasta llegar a los manglares ubicados en el Pacífico, han sido considerados como un factor de riesgo y contaminación, debido a la presencia de enfermedades en humanos y ganado, lo cual ha traído cambios en las actividades agrarias y en las pautas de consumo ribereño, como es el caso de los ríos Cintalapa y Cacaluta, asimismo, ha reconfigurado las relaciones intra e intercomunitarias.

El cercamiento de antiguas áreas de tránsito cotidiano para el pastoreo, y de camino de vuelta a la parcela o acarreo de cosechas, como lo muestra la siguiente ilustración, ha perjudicado también las labores de captación de agua ahí desarrolladas, ya que las comunidades rurales administran este líquido vital mediante la integración de comités de agua, estructura comunitaria dedicada a controlar su distribución. La privatización de las áreas concesionadas para la minería, en coincidencia con las rancherías en donde se ubican las tomas de agua, impidió realizar las labores del comité, y además las maquinarias taparon las tuberías y desecharon residuos en los ríos, causando inconformidad entre las comunidades localizadas "aguas-abajo".

\section{Figura 2. Cercamiento de los antiguos lugares de camino cotidiano,} comunidad de Jalapa, lote "El Encuentro" concesión Casas Viejas

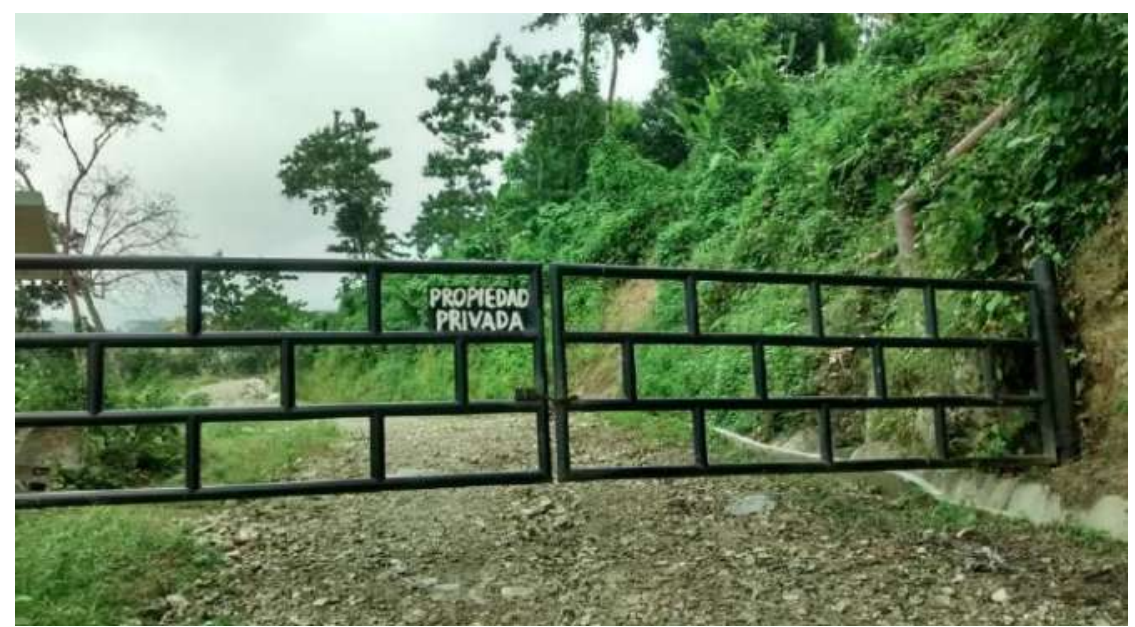

Fuente: archivo personal (2016). 
Por otra parte, la realización del trabajo de campo en el Soconusco permitió conocer el esquema de operación del extractivismo minero, en donde las filiales y las trituradoras mexicanas tienen una particular importancia en los nodos de movilidad, que dan salida a los minerales fuera de la región, mediante su transporte y embarque desde Puerto Chiapas, ubicado en Tapachula, hacia los espacios globales de comercio que tienen como destino principal Beijing en China.

Ese traslado comenzó en el año 2011, con 1500 toneladas de titanio, en el siguiente año se extrajeron barita, magnetita, ilmenita, hierro, acero y titanio, por parte de las empresas: Obras y Proyectos Mazapa e Industrias Unidas de Cobalto. En el caso del titanio, se exportaron 559,369.9 toneladas hacia diversos puertos de China, entre ellos Caofeidan y Hong Kong, y posteriormente otras 103,809 toneladas entre el año 2012 y 2014, (API-Puerto Chiapas, 2012 y 2014).

Debido a la creciente importancia de las minas, localizadas en Acacoyagua y las mineralizaciones en la sierra y la zona costera, se promovió la creación de una terminal especializada para minerales y trituradoras, concesionada a capital chino (API-Puerto Chiapas: 2016). En este punto, la declaración de la región como Zona Económica Especial (ZEE) en el año $2017^{4}$, tiene que ver con su integración en los circuitos globales de acumulación de capital, que facilita la salida de los commodities dispuestos en Puerto Chiapas, punto estratégico para su exportación (SE/SGM: 2015).

\section{Configuración del campo de conflicto}

La oposición de las comunidades, a la privatización de los espacios demarcados desde la cotidianeidad rural, originó una red de relaciones en defensa del agua por parte de las rancherías "aguas-abajo" aledañas a las zonas de mina, cuestión que causó confrontación con los representantes legales de las empresas. Sin embargo, la falta de interés por parte de las instancias gubernamentales involucradas en regular el sector minero y vigilar esta área de conservación ${ }^{5}$, en la cual existían evidencias de devastación natural, enfermedades dermatológicas y cancerígenas ${ }^{6}$, propició la manifestación pública del problema de manera paralela en los municipios de Escuintla y Acacoyagua en el año 2014.

En ese sentido, los daños en el entorno como experiencia compartida inciden en el señalamiento de la minería como un factor de riesgo y vulnerabilidad, sumado a la actividad sísmica ${ }^{7}$ y los eventos climatológicos como tormentas y huracanes (ValderramaLanderos et al., 2017).

\footnotetext{
${ }^{4}$ Esta denominación jurídica ofrece ventajas de inversión, arancelarias y de otro tipo para megaproyectos forestales, agroindustriales, de conservación y de turismo.

${ }^{5}$ Comisión Nacional de Áreas Naturales Protegidas (CONANP), Comisión Nacional Forestal (CONAFOR), Comisión Nacional del Agua (CONAGUA), Procuraduría Federal de Procuración Ambiental (PROFEPA), Secretaría de Medio Ambiente y Recursos Naturales (SEMARNAT), Procuraduría Agraria (PA), Registro Agrario Nacional (RAN), Secretaría de Economía (SE).

${ }^{6}$ Testimonios señalan que a partir del año 2009 el contacto con los ríos se tradujo en problemas dermatológicos, por tanto, los habitantes dejaron de consumir agua y peces de los afluentes.

${ }^{7}$ Las zonas mineralizadas convergen con las placas tectónicas de Cocos, americana y del Caribe, las fallas Polochic-Montagua y Motozintla-Chicomuselo.
} 
El surgimiento del Frente Popular en Defensa del Soconusco (FPDS) a mediados del año 2015, es resultado de las protestas locales previas ante el reconocimiento de la minería como un problema común, a partir de la compartición de experiencias y de la acción colectiva regional, ante la indiferencia de las autoridades en sus cuatro niveles de gobierno. Algunos de los procesos deliberativos más importantes, han sido la celebración de asambleas para la firma de actas declaratorias municipales, de territorios libres de minería y la instalación de campamentos de vigilancia comunitaria en octubre del año 2016, en los puntos estratégicos para evitar el flujo de mineral: la carretera de la ranchería de Jalapa, La Cadena, al pie del ejido Los Cacaos.

Lo anterior, fue causa de inconformidad entre los prestadores de servicios a las empresas mineras y entre segmentos de pobladores en el nivel regional, lo que incentivó la conformación de un campo de conflicto y se identificaron oposiciones. Desde entonces, se evidencian los desacuerdos entre pobladores y/o autoridades agrarias que rechazan la minería, y entre aquellos que sí la aceptan, cuestión que propició el tráfico ilegal de minerales por las noches. En contraposición, se da el fortalecimiento organizativo de las guardias comunitarias y de las redes de relaciones regionales, que han reivindicado los bienes naturales como base de la reproducción de la vida y como parte de un territorio compartido.

Esto ha implicado la manifestación y confrontación de los opositores en distintos espacios públicos. La visibilidad del conflicto, originó que a finales del año 2016, la Subsecretaría de Gobierno de Chiapas convocara al diálogo entre el movimiento social, los habitantes de las comunidades afectadas y las empresas mineras en la región, integrando comisiones de trabajo en materia agraria, sanitaria y ambiental; sin embargo, el comité científico de esta última, desconoció la interlocución, debido a la inexistencia de documentación que acreditara las actividades mineras en la región y a la falta de profesionalismo en la elaboración de los protocolos de investigación, que dieran cuenta de sus impactos. Ello repercutió en la ruptura del diálogo en abril del año 2017, pues también hubo un señalamiento de las partes como promotores de discordias, corporativismo de mano de los operadores mineros y desconfianza hacia las autoridades consideradas partícipes en los procesos de instalación de las empresas.

Los acontecimientos referidos, permiten que los actores regionales se involucren en el problema de manera segmentada, así como, la configuración de relaciones sociales antagónicas en red, lo cual ha implicado el acoplamiento del ciclo de la protesta en correspondencia con los ciclos agrarios, la demarcación y resignificación de distintos espacios públicos como lugares de convivencia, peligro, confrontación y contención, lo cual da cuenta de los patrones de visibilidad y latencia de la disputa, en torno de los recursos como valor de uso o como valor de cambio.

En esta situación, los accesos cercanos a la mina, los campamentos de vigilancia para detectar la actividad en la mina, la plaza cívica y otros referentes situados en las comunidades, se han constituido como lugares de manifestación de poder, disputa y acuerpamiento político; en ellos se involucran las redes de alianza y confrontación comunitario-regional en defensa de los territorios, o en su defecto, en apoyo a la minería. El siguiente cuadro expone los nodos en el nivel ejidal y regional que intervienen en el campo del conflicto. 


\section{Cuadro 1 Redes multiescalares en el campo del conflicto}

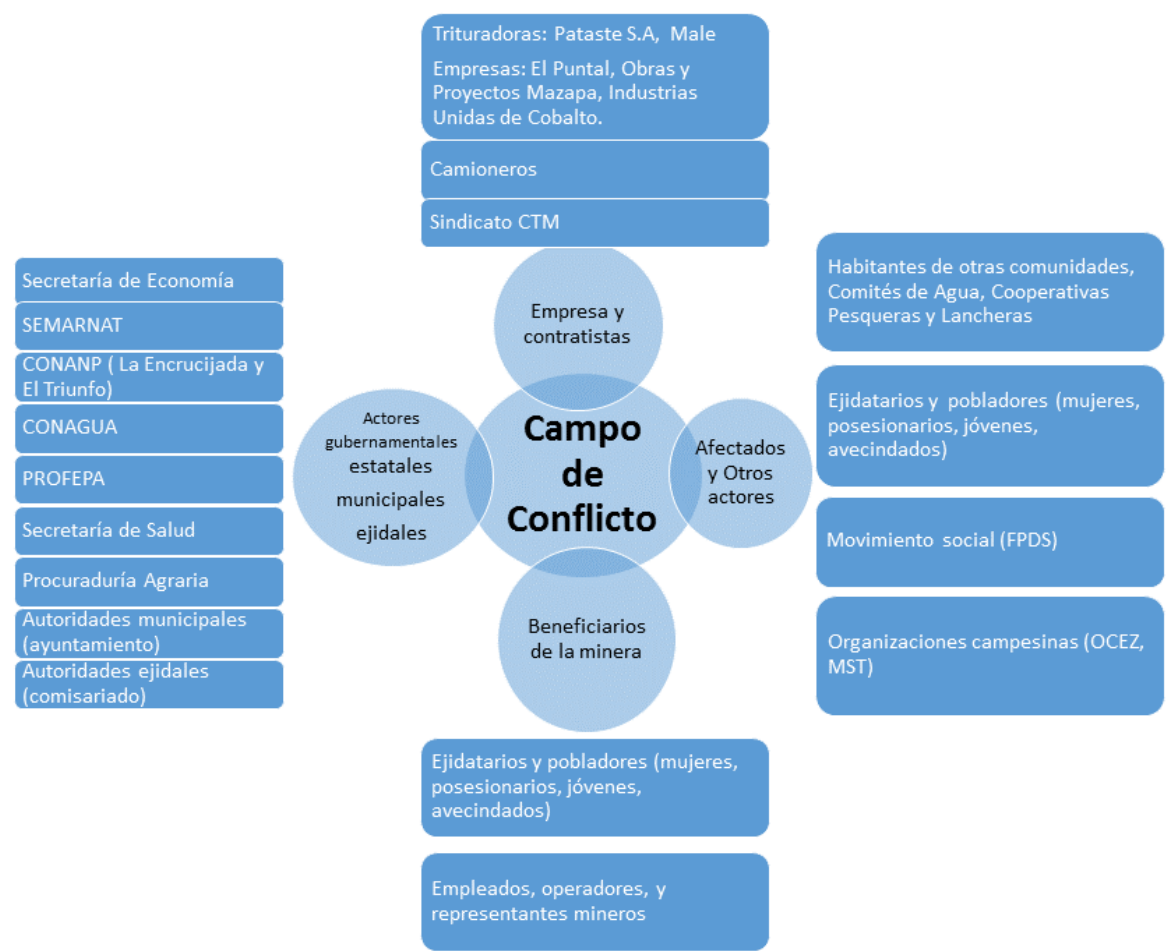

Fuente: presente investigación.

\section{El caso de la comunidad rural los cacaos: entre el cafetal y el mineral}

Los Cacaos, forma parte del municipio de Acacoyagua, comparte la geografía de montaña con las comunidades Satélite Morelia, Magnolia y Las Golondrinas. Se formó en 1925, en parte de los terrenos de la finca de propiedad japonesa Cintalapa, la dotación de tierras resultó de la petición de los jornaleros guatemaltecos, incorporados a la estructura agraria posrevolucionaria como ejidatarios. Desde entonces, se incentivó la siembra de café borbón y cacao nativo, sobre todo tras el surgimiento de las instituciones centrales para la organización de los productores, acopio, procesamiento y comercialización, entre las cuales destaca el Instituto Mexicano del Café (1959), y la Banca del Crédito Rural (Renard, 1993, Villafuerte, 1993).

La modernización del sector agrario y los cambios en la política económica entre 1980 y 1994, significaron la apertura a la competencia internacional en el contexto de la globalización, la caída de los precios comerciales del café (Von Mentz, 1998), la desaparición de las instancias gubernamentales promotoras de la cafeticultura, y la focalización de los programas para el campo.

A pesar de la crisis productiva derivada de la desregulación del sector, que implica el acopio y comercialización dentro de las redes del coyotaje en provecho empresarial y factores ambientales como el cambio climático y las plagas, existe continuidad entre los ciclos cafetaleros y las formas de vida. Sin embargo, el fin del reparto agrario guberna- 
mental, ha implicado que los ejidatarios subdividan las parcelas entre sus descendientes, y ante el agotamiento de tierras, los más jóvenes se incorporen en la división del trabajo dentro de la unidad doméstica, o bien, opten por la migración laboral.

En este contexto, la SE otorgó una concesión minera a la empresa El Puntal que comprende del año 2009 al 2059 para extraer titanio, oro, plata y hierro mediante el proyecto "Casas Viejas" que abarca 90\% del ejido (CGMinería, 2017). Sin embargo, los vínculos que permiten el acceso de la empresa El Puntal, dependen de una cadena de acciones en el nivel local, en especial con los ejidatarios con cargos en la mesa directiva del comisariado ejidal, ya que orientan los acuerdos en condiciones asimétricas con el resto de la comunidad.

La celebración de un primer encuentro en la Casa Ejidal, tuvo por objetivo formalizar el beneficio económico en favor de los ejidatarios por la cantidad de dos dólares por tonelada obtenida de titanio, y los acuerdos individuales en los predios de donde se obtendrían los minerales, con base en un ofrecimiento de quinientos pesos por tonelada de roca. Como resultado de esta asamblea ejidal extraordinaria, se acordó aceptar las actividades de exploración minera mediante la realización de un acta, que con el paso del tiempo fue considerada ilegítima por un segmento de los pobladores ${ }^{8}$. Sin embargo, ello derivó en la ocupación temporal de una superficie de 500 hectáreas.

En ese sentido, las jerarquías sociales en el interior de la comunidad en relación con las zonas mineralizadas, en donde se encuentran minerales, y con los puntos estratégicos para dar salida a estos, fundamentan los acuerdos entre la empresa y los ejidatarios, para la venta o renta de parcelas indicadas para desarrollar la actividad minera. Ello define las condiciones de los tratos asimétricos con los demás habitantes de la comunidad, e incluso por fuera de la propia estructura agraria, en función del papel ocupado en la jerarquía social (ejidataria/o, posesionaria/o, avecindada/o, madre o joven), y su relación con la existencia de altas mineralizaciones en las parcelas, (con pagos que oscilan entre los veinte mil a un millón de pesos) para permitir la exploración geológica.

Por otra parte, los representantes de la empresa El Puntal generaron expectativas laborales entre los demás pobladores y aseguraron la mejoría en infraestructura, clínicas e incluso un parque. Sin embargo, con el paso del tiempo sus ofrecimientos se redujeron a la contratación para las labores de acarreo mineral en camiones de volteo operados por la CTM, así como el abasto de despensas operado por el programa social Prospera. Así, el condicionamiento de transferencia de beneficios, transforma el intercambio en una relación de poder, pues como menciona (Barquin, 2015), los recursos poseídos y posiciones sociales asimétricas, son aprovechados intencionalmente para que el otro haga algo que de otro modo no haría.

Así, el cuestionamiento comunitario sobre los beneficios de la minería, expone las tensiones que prefiguran el conflicto, entre los habitantes que están de acuerdo con la estancia de la empresa El Puntal, con el objetivo de obtener provecho económico o laboral, y los inconformes que perciben su entrada como un engaño al no cumplir acuerdos, sobre todo por la apropiación utilitaria de los lugares fundamentales en los ciclos producti-

\footnotetext{
${ }^{8}$ Debido a la desactualización del padrón ejidal e incumplimiento de la Ley Agraria (emisión de convocatoria 30 días previos, certificación y validación por parte del Registro Agrario), y la especificación del acuerdo solamente para exploración (análisis geológicos de minerales).
} 
vos del café y el cacao, el trazo de carreteras clandestinas y la devastación de los recursos naturales por la extracción mineral.

Debido a ello, en el año 2014, se objetó la producción minera por iniciativa sobresaliente de la población juvenil y las mujeres, en una asamblea convocada el 30 de marzo, en la cual se expuso el problema en la comunidad, y un segmento de ejidatarios arrepentidos apoyaron la firma del acta de asamblea que enunciaba la voluntad opositora mayoritaria. Lo anterior, ha orientado nuevos cauces de socialización, cuyas valoraciones divergentes expresan la importancia de la tierra y el ambiente como sustento de las formas de vida rural, entre quienes se auto adscriben como "antimina", y, por otro lado, quienes son considerados beneficiarios de las relaciones dinerarias mineras que son denominados como "mineros". La oposición de estos actores en el espacio público comunitario, fue fundamental para la configuración del campo del conflicto, que ha implicado la fragmentación de relaciones sociales, vecinales y familiares, y también para la orientación de la acción en torno al conflicto.

Precisamente, la interacción intercomunitaria hizo del conocimiento regional la problemática señalada, sobre todo, en otras comunidades que atravesaban la misma situación: en la Libertad y en Nueva Francia. Los sucesivos ejercicios de compartición de historias, cuyo común denominador fue el sacar a la luz los efectos en el ambiente y los daños en la salud asociados a la inserción de las empresas mineras desde hace al menos diez años, favorecieron el surgimiento y sostenimiento de relaciones intercomunitarias, en torno a la disputa por la disposición/apropiación de los bienes del subsuelo y otros referentes de lugar relacionados con las actividades agrarias.

Al mismo tiempo, implicó la conformación de una red de acciones colectivas que se podría denominar "antimina", las que resultaron en la participación del ejido Los Cacaos en las estrategias regionales en oposición a la minería, entre las cuales destaca la conformación de los plantones de vigilancia para impedir la extracción de mineral, y la puesta en marcha de una serie de acciones legales. También permitió constituir una red de relaciones "mineras", esto es, acciones en pro de la minería expresadas públicamente, a partir de la celebración del diálogo convocado por la Subsecretaría de Gobierno, en el contexto del ascenso de la oposición a la minería, pues en las mesas de negociación participaron representantes de las empresas mineras, instancias involucradas en la regulación del sector, autoridades agrarias, transportistas que trabajaban para la empresa, ejidatarios favorables a la minería y pobladores opositores, todo ello bajo la idea de "atender a todas las partes".

Lo anterior, pone de relieve el alcance del problema en la disputa regional, ya que el caso de Los Cacaos, expone el cúmulo de irregularidades bajo las cuales operan los proyectos mineros regionales, cuyas denuncias de ilegalidad evidenciadas por los habitantes mediante su arqueología del saber ${ }^{9}$ dan cuenta de la omisión gubernamental en torno de los daños ambientales, sobre todo tras la ruptura del diálogo por la entrega de dictámenes a destiempo, incumplimiento de acuerdos, y el rechazo de los habitantes favorables a la minería a someterse a los protocolos oncológicos, lo cual favoreció la reali-

Se retoma este concepto de (Foucault 2005, p.p. 305-307). En el texto, se entiende la necesidad de los habitantes de la región, por evidenciar materialmente los componentes en los procesos de extracción minera y las transformaciones en el territorio. 
zación de estudios sanitarios parciales, que derivaron en el desconocimiento de las enfermedades asociadas a la minería por parte de la Secretaría de Salud, y en consecuencia, la aprobación de la presencia de las empresas en cuestión.

En ese sentido, aunque esta disputa no es única en la región, ilustra las redes de interacción que dan cuenta de un campo de conflicto que se superpone con las estructuras regionales, y que en lo que concierne a la extracción de minerales, implica acuerdos y desacuerdos, tratos económicos, tránsitos e interacciones que exceden el área ejidal, ya que también existen consecuencias en el nivel de cuenca y en las comunidades con las que converge "aguas-abajo", cuyos atributos son fundamentales en la disputa. Ello, sobre todo, por el matiz de violencia plural (Martínez, 2017, p.17) que ha adquirido distintas formas de expresión, como la agresión simbólica, física o coerción y que definen relaciones de poder, pero cuyas redes de acciones intercomunitarias y legales, han derivado en la suspensión de la minería en la región por parte de las comunidades desde hace dos años, y aun cuando las empresas impugnan la legalidad de dicha actividad, la PROFEPA ha reconocido recientemente su suspensión.

\section{Los Cacaos: más allá de la cuestión minera}

La inserción de la minería en la comunidad de Los Cacaos, se enmarca en condiciones macroestructurales y sociopolíticas que incentivaron su incorporación espacial, en la lógica de apropiación utilitaria en el escenario de la globalización económica. Estas, se encuadran en las contradicciones derivadas del cambio de paradigma agrario, cuya consecuencia es la exclusión de las generaciones jóvenes, en la participación de la toma de decisiones como sujetos de derecho, instituida históricamente en asociación con la titulación de tierras ejidales. El no incluir a los jóvenes en la votación o en la ocupación de cargos en la estructura ejidal, ponen de relieve la figura jerárquica de la autoridad agraria, que fue central para el impulso de la asamblea, que consolidó los tratos asimétricos entre los demás ejidatarios y la empresa El Puntal.

La inserción de la minería, expone las tensiones y límites de las formas históricas de participación, en especial el cuestionamiento al ejercicio de autoridad, por parte de las generaciones que están incorporadas de manera diferenciada en la estructura agraria, aun cuando están plenamente incorporadas a las actividades agrarias (jóvenes escolarizados y mujeres, en condición de posesionarios, avecindados o sin tierra), excluidos como sujetos involucrados en los procesos de decisión, aun cuando hayan vivido toda su vida en la comunidad, ya que no poseen 3 hectáreas de parcela como mínimo, y por ello, no estar inscritos en el padrón de ejidatarios.

La coincidencia de la carencia de tierras, y, por tanto, del derecho a decidir, ha generado una tensión intergeneracional en el contexto del conflicto, que expresa los límites de la asamblea de ejidatarios como forma de organización comunitaria. Esta es una inquietud expresada por los inconformes con la minería, al cuestionar su impulso en relación con el ejercicio de autoridad, por lo cual, exigen ser tomados en cuenta en temas cruciales presentes y futuros. 
De acuerdo con ello, el conflicto derivado de la actividad minera ha generado dos posturas al interior de la directiva de representación ejidal, sustentadas en la disputa por la sucesión de cargos de representación en la mesa directiva del comisariado ejidal. Al tomar mayor fuerza el conflicto por la valoración divergente en torno a los recursos, se conformaron dos facciones que dan cuenta de la división interna centrada en dicha cuestión, así como, del papel de la autoridad en el problema.

Existe un bloque vinculado con los empresarios mineros y operadores regionales, con una estrategia de cercanía entre candidatos a comisariados ejidales, mesas directivas, ejidatarios y habitantes favorables a la minería, para salvaguardar los apoyos y beneficios personales. Esto ha repercutido en los procesos de renovación de cargos en las directivas ejidales, que se llevan a cabo cada tres años, pues al menos en las últimas dos elecciones el cargo de presidente del comisario ejidal se ha ligado a este grupo. Por otra parte, existe un grupo que vincula a ejidatarios y opositores a la minería, la estrategia de estos ha sido la inclusión de los demás pobladores en las asambleas ejidales y otros ámbitos de participación extraejidal, en las exigencias hacia las autoridades y la negociación con el gobierno. Los habitantes asociados en este grupo, han tenido éxito en la ocupación de cargos como jueces y tesoreros ejidales, pero no han logrado nunca que su candidato sea electo para presidente del comisariado ejidal.

En este contexto, la asamblea de pobladores ha tomado mayor importancia como espacio de expresión y deliberación en temas de relevancia comunitaria, después de la notoriedad del conflicto derivado de la extracción minera. Una consecuencia de ello, es la inclusión de jóvenes y mujeres sin derechos agrarios en los espacios de organización política dentro y fuera de Los Cacaos, procesos detonados por la lucha contra la minería. Esto ha puesto de manifiesto su importancia como miembros activos en la vida comunitaria, a partir del liderazgo en los eventos realizados en contra de la actividad en cuestión: marchas, peticiones municipales, asambleas, como representantes comunitarios en el diálogo con la Subsecretaría de Gobierno, en el FPDS, en los comités de salud y educación, y como agentes organizativos. Paradójicamente, las personas que han adquirido mayor liderazgo y participación a partir del conflicto, son quienes tienen menor posibilidad de ser tomados en cuenta en las decisiones comunitarias, así como en la elección u ostentación de cargos comunitarios.

Finalmente, existen muchas situaciones que ejemplifican las tensiones respecto de la participación de los habitantes, en las decisiones comunitarias (firmas de actas de inconformidad, celebración de asambleas, información) y la unilateralidad centrada en la figura del presidente del comisariado ejidal, inexplicable sin la consideración del peso, tanto de la estructura interna como del ámbito municipal/estatal, ello no solamente transforma el sentido de lo político del lugar, pues la oposición a la minería se enmarca en condiciones macroestructurales que encuadran con las estructuras agrarias, pone de manifiesto la desconfianza en la autoridad en todos los niveles: ejidal, municipal y estatal, al tiempo que busca denunciar esquemas de corrupción e injusticia, cuestión que finalmente ha generado rupturas en la vida de los lugareños, la relación entre autoridades y pobladores, que inciden en la revaloración del espacio público y la asamblea como espacio de ejercicio de derechos y defensa de los mismos, cuestionando los límites de las formas tradicionales de las asambleas agrarias históricas en el nivel comunitario. 


\section{Conclusiones}

Hasta aquí, se puede observar que la divergencia de valoraciones e intereses en torno a la apropiación de los bienes, por los cuales se disputa en el contexto del conflicto analizado, orientan los comportamientos y la identificación de dos agrupaciones diferenciales que se han autodenominado como minera y antiminera, y que actúan en distintos espacios de interacción públicos y privados, identificándolos como lugares de contención y confrontación. Si bien, no hubo espacio para mostrarlo de manera amplia, se logró identificar que esas valoraciones e intereses diferenciales, atraviesan las relaciones de socialización en el entorno comunitario, esto es, en la familia, en lo religioso, vecinales y escolares.

Lo anterior, manifiesta un conflicto surgido también por las distintas valoraciones alrededor de los recursos naturales: como base para la reproducción de formas de vida para unos, y preeminentemente económicos para otros. Valoraciones divergentes, que hasta antes de la llegada del extractivismo minero no se habían manifestado de manera abierta y permanecían latentes, por lo cual la inserción de la minería es considerada por muchos, además de un elemento de contaminación, incertidumbre y riesgo para las distintas formas de vida (actual y futura), tomando en cuenta la comparación del antes y después de esta actividad, un factor de conflicto.

Tomando en consideración lo anterior, desde la etapa de la exploración minera, pasando por la sucesiva negociación con las comunidades y la activación de la extracción, implican distintos puntos de contacto entre empresa minera y comunidad, cuestión que permite entender el conflicto, no como un hecho, sino como un proceso que va adquiriendo matices y niveles de confrontación, dependiendo del contexto en el cual se suceden distintas situaciones, y que van reconfigurando también las redes de relaciones, niveles de actuación institucional y estrategias de organización que están implicadas en el problema y que se vinculan con las coyunturas, periodos de latencia y visibilidad, por lo cual, lejos de pensar en el equilibrio estructural, la escalada del conflicto en relación con los ciclos agrarios y los ciclos de la protesta, expone los matices, puntos críticos de las relaciones y su modificación en el interior de la comunidad y del campo del conflicto, cuestión que permite concebirle como un proceso.

Así, el trabajo muestra que la llegada de la minería no se impone como un determinismo de la empresa hacia la comunidad, sino que, es necesario considerar la importancia de las condiciones económicas, políticas y sociales de las comunidades que intervienen en la aceptación de su entrada, a partir de las ventajas que ofrecía su inserción y permanencia tanto en el nivel macro como en el micro, y que determinaron la aceptación inicial de las empresas. De ahí que no se imponen en definitiva de manera determinista, como se destaca a partir del estudio de caso y se puede generalizar en la región del Soconusco. Esto expone la importancia de la agencia de los sujetos y la emergencia posterior de un cuestionamiento en las condiciones de aceptación de la minería, que lleva al arrepentimiento de segmentos poblacionales que pugnan por la salida de las mineras, y cuyas acciones deliberativas, legales y colectivas mantienen suspendida hasta hoy la minería indefinidamente. 
Finalmente, se trata de un caso paradigmático que expone la relación localregional de los conflictos mineros, desde este marco destaca la participación de actores con intereses divergentes, la omisión y falta de transparencia en torno de los proyectos que se impulsan, en donde juegan un papel relevante los nexos estatales, la sociedad civil y otros agentes, lo cual evidencia algunos de los aspectos que caracterizan lo que se suscita en el panorama minero mexicano.

\section{Referencias bibliográficas}

Abélés, M., y Baradó, M. (2015). Los encantos del poder. Desafios de la antropología política. Buenos Aires: Siglo XXI.

API-Puerto Chiapas (2012). Nuevo producto potencial en Puerto Chiapas. Recuperado de: http://www.puertochiapas.com.mx/noticias/230-nuevo-producto-potencial-enpuerto-chiapas.

API-Puerto Chiapas (2014). Exportación de titanio. Recuperado de: http://www.puertochiapas.com.mx/noticias/319-exportacion-de-titanio-alcanza-las103809-toneladas-en-puerto-chiapas.

API-Puerto Chiapas (2016). "Actividades portuarias y tipo de carga". Recuperado de:http://www.puertochiapas.com.mx/actividades-portuarias-y-tipos-de-carga. Fecha de consulta: 16 mayo 2018.

Balandier, G. (1969). Antropología Política. Barcelona: Península.

Barquin, A. (2015). Antropología y poder político. El ejercicio de poder en las políticas de educación intercultural. México: INAH.

Masagualli, N., y Bolaño, O. (2017). Alternativas de poder político en los movimientos sociales-rurales de Colombia: caso Organización Indígena del Norte del Cauca. Collectivus. Revista de Ciencias Sociales, 4(2), 36-54. DOI: https://doi.org/10.15648/Coll.2.2017.3

Cardoso, F. H y Faletto, E. (1994). Tipología del desarrollo hacia afuera. En R. M. Marini y M. Millán (comps.), La teoría social latinoamericana. Tomo II (p.p. 125-138). México: UNAM.

CGMinería. (2017). Tarjeta de Registro Informativa: Lote Casas Viejas, titulo vigente 233435. Recuperado de: https://tarjetarpm.economia.gob.mx/tarjeta.mineria/.

Cohen, A. (1979). Antropología política: el análisis del simbolismo en las relaciones de poder. En J. Llobera (comp.), Antropología Política (p.p.55-82). Barcelona: Anagrama.

Coser, L. A (1961). Las funciones del conflicto social. México: FCE.

Damián, A. (1988). Conformación de la región del Soconusco, Chiapas. Estudios Fronterizos, 7 (17), 61-80.

Díaz, R. (2005). El persuasivo espectáculo del poder. Rituales políticos y ritualización de la política. En P. Castro (coord.), Cultura política, participación y relaciones de poder (p.p. 97-117) México: UNAM/Colegio Mexiquense.

Dirección General de Minas/Dirección de Cartografía (2017). Concesiones mineras. Recuperado de http://www.datos.economia.gob.mx/RegulacionMinera 
Evans-Pritchard, E.E. (2010). Los nuer de Sudán. En M. Fortes. y E.E Evans-Pritchard (Eds.), Sistemas políticos africanos (p.p. 405-438). México: CIESAS/UAM/Universidad Iberoamericana.

Foucault, M. (2005). La arqueología del saber. México: Siglo XXI.

Gaceta Parlamentaria (2014). Dictamen de la Comisión de Medio Ambiente y Recursos Naturales número 4117-IV'. Recuperado de: http://gaceta.diputados.gob.mx/Black/Gaceta/Anteriores/62/2014/sep/20140923IV/DictamenaD-29.html.

Gluckman, M. (2003). Analysis of a Social Situation in Modern Zululand, traducción. Revista Bricolage, (1), 34-49.

Gudynas, E. (2010). Agropecuaria y nuevo extractivismo bajo los gobiernos progresistas de América del Sur. Territorios, (5), 37-54.

Harvey, D. (2006). La acumulación por desposesión. En C. Bueno y M. Pérez (coords). Espacios globales (p.p. 21-52). México: Universidad Iberoamericana/Plaza y Valdez.

Hernández, R. A. (1998). Indigenismo y desarrollo en la frontera sur chiapaneca. Comercio exterior, 48 (5), 397-409.

Lamberti, M. J. (2011). Una lucha a cielo abierto. El caso del Frente Amplio Opositor a Minera San Xavier. En H. Alimonda, La naturaleza colonizada. Ecología política en América Latina (p.p. 303-332). Buenos Aires: CLACSO-CICCUS.

Mançano, B. (2010). Acerca de la tipología de los territorios. En C. Rodríguez (coord.), Defensa comunitaria del territorio en la zona central de México. Enfoques teóricos y análisis de experiencias (p.p. 57-75). México: Juan Pablos Editor.

Martínez, J. (2004). El Ecologismo de los Pobres. Conflictos ambientales y lenguajes de valoración. Barcelona: Icaria.

Martínez, L. (2017). Género, juventud y violencia simbólica: miradas cualitativas desde la diversidad juvenil en San Luis Potosí, México. Collectivus, Revista de Ciencias Sociales, 4 (1), 12-40. DOI: https://doi.org/10.15648/Coll.1.2017.2

Miranda, R. (1982). La economía cafetalera y oncocercosis en la región Soconusco, Chiapas (Tesis en Antropología Social). México: ENAH.

Moreno, S. y Abraján, P. (2016). Minería a cielo abierto, la nueva amenaza de la Sierra Madre de Chiapas. México: FONCET.

O’Connor, J. (2001). Causas naturales. Ensayos de marxismo ecológico. México: Siglo XXI.

Pohlenz, J. (1978). La formación de las plantaciones cafetaleras del Soconusco y el capitalismo en Chiapas. En Simposio La hacienda mexicana en el cambio (siglo XIX-XX) (p.p.1-26). México: Centro de Inv. Regionales (Univ. De Yuc.) y Centro de Inv. Ecológicas del Sureste.

Renard, M. C. (1993). El Soconusco. Una economía cafetalera. México: COLMEX/Universidad Autónoma de Chapingo.

Rodríguez, C. A (2010). Defensa comunitaria del territorio en la zona central de México. Enfoques teóricos y análisis de experiencias. México: Juan Pablos Editor.

Santacruz de León, E. E. (2009). Atraso económico, migración y remesas: el caso del Soconusco, Chiapas, México. Revista de Ciencias Sociales, 16 (50), 57-77.

SE/SGM (2015). Panorama Minero del Estado de Chiapas. Chiapas, México: Secretaría de Economía. 
Schmitt, C. (1998). El concepto de lo politico. Madrid: Alianza.

Silva, L. (2010). Implicaciones sociales en la legislación ambiental: el proceso de evaluación de impacto ambiental de Minera San Xavier. En G. Delgado (coord.), Ecología política de América Latina (p.p. 213-250). México: CEIICH/UNAM.

Simmel, G. (2010). El conflicto. Sociología del antagonismo. Madrid: Sequitur

Spenser, D. (1998). Los inicios del cultivo de café en Soconusco y la inmigración extranjera. En B. Von Mentz, et al (coords.), Los empresarios alemanes, el tercer reich y la oposicion de derecha a cardenas (p. 65-78). México: CIESAS.

Svampa, M. (2010). Movimientos sociales, matrices socio-políticos y nuevos escenarios en América Latina. Recuperado de: http://kobra.bibliothek.unikassel.de/bitstream/urn:nbn:de:hebis:34-2010110334865/1/OWP.

Touraine, A. (1994). ¿Qué es la democracia?. México : FCE.

Turner, V. (2002). Mukanda, circuncisión de los muchachos. Las políticas de un ritual no político. En I. Geist (comp.),Antropología del ritual. Victor Turner (p.p. 13-34). México : INAH/ENAH.

Valderrama-Landeros, I.H et al. (2017). Manglares de México. Actualización y exploración de los datos del sistema de monitoreo 1970/1980-2015. México: CONABIO.

Van Velsen, J. (2007). El método del Caso-Ampliado y el Análisis Situacional. Revista Bricolage, (14), 44-54.

Villafuerte Solís, Daniel (1993). El café en la frontera sur. La producción y los productores del Soconusco, Chiapas. México: Gobierno de Chiapas/Instituto Chiapaneco de Cultura.

Von Mentz, B. (1998). Empresas mercantiles y fincas cafetaleras en la década de 19101920. En Los empresarios alemanes, el Tercer Reich y la oposición de derecha a Cárdenas (p.p. 89-117). México: CIESAS.

\section{Referencias para la elaboración de mapas}

CONANP (2017). Comisión Nacional de Areas Naturales Protegidas. Recuperado de: http://sig.conanp.gob.mx/website/pagsig/.

Dirección General de Minas/Dirección de Cartografía (2017b). Recuperado de: htth://www.datos.economia.gob.mx/RegulacionMinera/Cartografia_Miner.z.

INEGI (2017). Instituto Nacional de Estadística y Geografía. Recuperado de: http://www.inegi.org.mx/geo/contenidos/geoestadistica/default.aspx.

SIAM (2017). Sistema de Información y Asignación Minera. Recuperado de: http://www.cartografia.economia.gob.mx/cartografia/. 